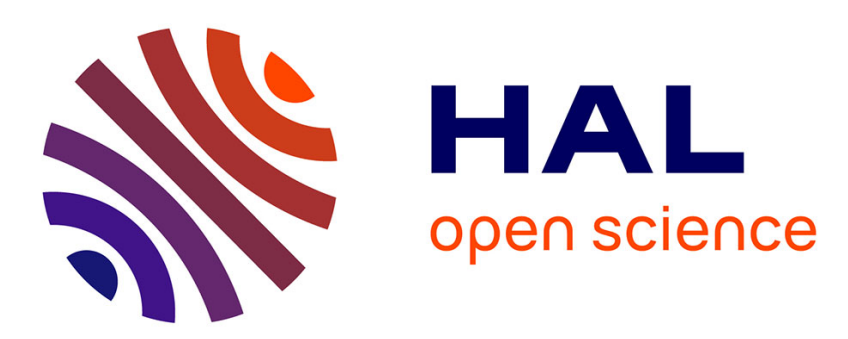

\title{
A review on surface heat and mass transfer coefficients during air chilling and storage of food products
}

\author{
Alain Kondjoyan
}

\section{To cite this version:}

Alain Kondjoyan. A review on surface heat and mass transfer coefficients during air chilling and storage of food products. International Journal of Refrigeration, 2006, 29 (6), pp.863-875. 10.1016/j.ijrefrig.2006.02.005 . hal-02955779

\section{HAL Id: hal-02955779 \\ https://hal.inrae.fr/hal-02955779}

Submitted on 5 Oct 2020

HAL is a multi-disciplinary open access archive for the deposit and dissemination of scientific research documents, whether they are published or not. The documents may come from teaching and research institutions in France or abroad, or from public or private research centers.
L'archive ouverte pluridisciplinaire HAL, est destinée au dépôt et à la diffusion de documents scientifiques de niveau recherche, publiés ou non, émanant des établissements d'enseignement et de recherche français ou étrangers, des laboratoires publics ou privés. 
Review Article

\title{
A review on surface heat and mass transfer coefficients during air chilling and storage of food products
}

\author{
Alain Kondjoyan* \\ Transfer \& Quality Modelling Team, Laboratory of Animal Products Quality, QuaPA, INRA, 63122 St Genès Champanelle, France
}

Received 30 August 2005; received in revised form 20 February 2006; accepted 24 February 2006

Available online 7 July 2006

\begin{abstract}
Heat and mass transfer coefficients are needed for the mathematical simulation of air chilling and storage of solid food products. Average transfer coefficient values and distributions around cylinders are now quite well known while it is not the case for solids of more complex shapes. CFD models are more and more often used to calculate transfer coefficient values on a single food product or packaging. Experimental knowledge is reviewed and the way it can be used by scientists and engineers to determine their own transfer coefficient values is illustrated. The potentials and limitations of present CFD models are illustrated and future improvements are also discussed.
\end{abstract}

(C) 2006 Elsevier Ltd and IIR. All rights reserved.

\section{Coefficients de transfert de chaleur et de masse lors de la réfrigération et de l'entreposage des produits alimentaires}

Mots clés : Produit alimentaire ; Réfrigération ; Entreposage frigorifique ; Enquête ; Transfert de chaleur ; Transfert de masse ; Coefficient

\section{Introduction}

In Europe, chilling of solid foods is most often achieved in an air stream. Airflow is also used to maintain a low temperature and/or high humidity ambience during storage. Heat/mass transfer modelling is needed to improve chilling/storage processes and functioning of industrial plants.

\footnotetext{
* Tel.: +33 4 73624492; fax: +33 473624089 .

E-mail address: alain.kondjoyan@clermont.inra.fr
}

In models, fluxes exchanged at the surface of products are mathematically described by Newton's law of convection which is very simple but requires the knowledge of the heat and the mass transfer coefficients. These coefficient values can be fitted against measurements but this procedure leads to inaccurate results, especially when evaporation is not taken into account and when measurements are taken under industrial conditions [1]. Introducing wrong coefficient values in models leads to calculated results which are erroneous. This paper reviews what is known about heat and mass transfer coefficients under air chilling and storage conditions. 


\begin{tabular}{|c|c|c|c|}
\hline \multicolumn{4}{|c|}{ Nomenclature } \\
\hline \multicolumn{2}{|c|}{ Latin symbols } & $T_{\max }$ & greatest of $T_{\text {air }}$ or $T_{\text {rad }}\left({ }^{\circ} \mathrm{C}\right.$ or $\left.\mathrm{K}\right)$ \\
\hline$A$ & constant & $T_{\mathrm{rad}}$ & temperature used to calculate radiant exchange \\
\hline$a$ & major axis of an elliptical cylinder (m) & & $\left({ }^{\circ} \mathrm{C}\right.$ or $\left.\mathrm{K}\right)$ \\
\hline$a_{\mathrm{w}}$ & water activity & $T_{\mathrm{s}}$ & temperature at the surface of the cylinder $\left({ }^{\circ} \mathrm{C}\right.$ or \\
\hline$B$ & constant & & K) \\
\hline$b$ & the minor axis of an elliptical cylinder (m) & $\mathrm{Tu}$ & free-stream turbulence intensity (flow direc- \\
\hline$D$ & cylinder diameter $(\mathrm{m})$ & & tion): $\sqrt{\overline{u^{2}}} / U(\%)$ \\
\hline$F$ & view factor & $\mathrm{Nu}$ & Nusselt number $=h L_{\mathrm{car}} / \lambda$ \\
\hline$H$ & cylinder height $(\mathrm{m})$ & $N u_{\text {car }}$ & characteristic Nusselt number $=N u / \sqrt{R e}$ \\
\hline$h$ & heat transfer coefficient $\left(\mathrm{W} \mathrm{m}^{-2} \mathrm{~K}^{-1}\right)$ & $u$ & velocity fluctuation around $U\left(\mathrm{~m} \mathrm{~s}^{-1}\right)$ \\
\hline$h_{\text {eff }}$ & effective heat transfer coefficient $\left(\mathrm{W} \mathrm{m}^{-2} \mathrm{~K}^{-1}\right)$ & $U$ & mean air velocity in the flow direction $\left(\mathrm{m} \mathrm{s}^{-1}\right)$ \\
\hline$L$ & $\begin{array}{l}\text { distance between objects in flow direction (ar- } \\
\text { rangement) }(\mathrm{m})\end{array}$ & $x$ & $\begin{array}{l}\text { curvilinear coordinate on the rim of an elliptical } \\
\text { cylinder }(\mathrm{m})\end{array}$ \\
\hline & characteristic length of a solid (m) & \multicolumn{2}{|c|}{ Greek symbols } \\
\hline $\begin{array}{ll}\text { Re } \\
P_{T}\end{array}$ & Reynolds number & $\varepsilon$ & emissivity of the solid surface \\
\hline$r$ & ratio of the major to the minor axis (elliptical & $\theta$ & $\begin{array}{l}\text { Angle from the stagnation point of a cylinder } \\
\text { (degree) }\end{array}$ \\
\hline$T$ & $\begin{array}{l}\text { cross-flow distance between objects (arrange- } \\
\text { ment) (m) }\end{array}$ & $\begin{array}{l}\lambda \\
\sigma\end{array}$ & $\begin{array}{l}\text { thermal conductivity of the air }\left(\mathrm{W} \mathrm{m}^{-1} \mathrm{~K}^{-1}\right) \\
\text { Stefan-Boltzmann constant }\left(\mathrm{W} \mathrm{m}^{-2} \mathrm{~K}^{-4}\right)\end{array}$ \\
\hline$T_{\text {air }}$ & air temperature $\left({ }^{\circ} \mathrm{C}\right.$ or $\left.\mathrm{K}\right)$ & Mean & \\
\hline$T_{\mathrm{d}}$ & dew point temperature $\left({ }^{\circ} \mathrm{C}\right.$ or $\left.\mathrm{K}\right)$ & $\bar{x}$ & mean of $x$ \\
\hline
\end{tabular}

\section{What is a transfer coefficient and how accurately shall it be known?}

When airflow makes contact with a solid food product, heat is exchanged by convection. As biological products are full of water, this water evaporates if the product is unwrapped. Energy can also been exchanged by radiation when product is totally or partly surrounded by walls whose temperatures are different from its own surface temperature. Very often the total energy exchanged at the surface of the food product by convection, radiation and evaporation is described using an effective transfer coefficient $[2,3]$ :

$$
h_{\mathrm{eff}}=\begin{gathered}
h \frac{T_{\mathrm{air}}-T_{\mathrm{s}}}{T_{\max }-T_{\mathrm{s}}}+F \varepsilon \sigma \frac{T_{\mathrm{rad}}^{4}-T_{\mathrm{s}}^{4}}{T_{\max }-T_{\mathrm{s}}}+k \Delta H \frac{P_{T_{\mathrm{d}}}-a_{\mathrm{ws}} P_{T_{\mathrm{s}}}}{T_{\max }-T_{\mathrm{s}}} \\
\text { convection } \rightarrow \text { radiation } \rightarrow \text { evaporation }
\end{gathered}
$$

During storage of stacks of products under free convection or mixed convection conditions, the energy exchanged by conduction between products in contact with each other can be of importance [4,5]. However, this is not the case under most industrial chilling-storage conditions. Under classical chilling conditions the energy exchanged by radiation is much lower than that exchanged by convection. It has been shown by Kuitche et al. [6] that neglecting radiation leads to an overestimation of $0.7^{\circ} \mathrm{C}$ of the temperature at the core, and $1.0{ }^{\circ} \mathrm{C}$ at the surface, of a single plaster cylinder subjected to an airflow with a velocity of $1.0 \mathrm{~m} \mathrm{~s}^{-1}$. The effect of radiation is much smaller for a product surrounded by others at similar temperatures. Thus the exact knowledge of $\varepsilon$ which is between 0.9 and 1.0 for food products, is not needed, and the variation of the energy exchanged by radiation is mostly due the view factor $F$ which can be determined analytically or numerically.

The energy exchanged by evaporation at the surface of unwrapped products is very important, especially at the beginning of chilling. It is about three times the energy exchanged by convection at the beginning of the chilling of a meat carcass from 40 to $7{ }^{\circ} \mathrm{C}$ under normal airflow conditions [6]. Under normal chilling and storage conditions the water activity of unwrapped fresh foods is always very close to one. Thus the uncertainty in energy exchanged by evaporation is directly related to the uncertainty on the value of the mass transfer coefficient. Heat and mass transfer coefficients are related to one another by the Lewis relation. This relation can be theoretically proved for a flat plate subjected to a laminar flow of air. It has also been experimentally validated for turbulent flows and products of complex shapes as well as under mixed convection conditions [7-9].

Finally, under usual chilling and storage conditions, the accuracy of calculated results relies mainly on the accuracy of the convective heat transfer coefficient value used in the model (mass transfer coefficient being deduced from this value). It was shown that during meat chilling a variation of $30 \%$ of the transfer coefficient value leads to a variation of $1.2-1.8^{\circ} \mathrm{C}$ of the temperature at the centre of a cylinder, $7 \mathrm{~cm}$ in diameter and of $1.9-2.6{ }^{\circ} \mathrm{C}$ at its surface. The effect 
tends to increase for low air velocities. A variation of $30 \%$ in the transfer coefficient leads to chilling time variations of about 15, 21 and $30 \%$ for air velocities of 2.0, 1.0 and $0.5 \mathrm{~m} \mathrm{~s}^{-1}$, respectively [6]. Thus accurate predictions of product surface temperature and weight loss require an uncertainty on the transfer coefficient less than or equal to $\pm 10 \%$ while an uncertainty of $\pm 25 \%$ is acceptable for the prediction of the core temperature. More detailed sensitivity analyses of the effect of a variation of the transfer coefficient on product temperature and weight loss during cooling can be found in $[10,11,12]$.

The forced convective transfer coefficient is directly related to the local thickness of the boundary layer which develops at the surface of the product. Thus it varies with the location on the solid surface. When the solid is a flat plate and when the plate is subjected to a laminar flow, the boundary layer thickness and the heat transfer coefficient value are easily calculated using analytical solutions $[13,14]$. When the surface of the solid is curved, flow separation occurs leading to wake formation. Transfer coefficients cannot be calculated analytically in wakes and numerical solutions have to be developed. The most studied curved surfaces are those of a sphere or an infinite cylinder placed cross-flow. Many experiments have been performed in wind tunnels to measure heat transfer coefficients around infinite cylinders and spheres. In wind tunnels, free-stream turbulence is artificially reduced to a very small value. On the other hand, in industrial plants airflows are highly turbulent due to fan movements and to wakes issued from upstream obstacles. Thus wind tunnel experiments cannot be used directly to determine transfer coefficient values. Average transfer coefficient values given by literature result from an interaction between: (1) the properties of the upstream airflow (average velocity and turbulence), and (2) the properties of the food product (shape, dimension and direction to the flow). Moreover average transfer coefficient values hide local differences which can be important to understand heterogeneities of treatments, for example in the case of slab-shaped products [15].

The first part of the paper reviews recent results on the effect of flow and product properties on the average transfer coefficient. The second part deals with the local variation of the transfer coefficient at the surface of a product and on the numerical calculations of transfer coefficients in turbulent flows.

\section{Effect of flow properties and product properties on the average transfer coefficients' value}

\subsection{Single product}

In some situations, product is chilled on its own or its direction relative to the airflow and its distance to others are such that it can be considered as a single product.

Under forced convection, heat and mass transfer coefficients around plates, cylinders and spheres are given in the literature by correlations of Nusselt or Sherwood numbers as functions of Reynolds number. Correlations express the decrease of transfer coefficient with product size and its increase with air velocity. But they cannot be directly applied to industrial situations as they do not take into account the effects of: (1) flow turbulence, (2) product shape and (3) product direction relative to the flow.

Turbulence is described by at least two parameters: turbulence intensity Tu, and integral scale. Turbulence intensity (standard deviation of the velocity divided by its average value and expressed in \%) is connected to kinetic energy of velocity fluctuations while integral scale characterises the size of the biggest vortices in the flow (distribution of small size vortices being theoretically universal for an isotropic turbulence). Increase of turbulence increases dramatically the average transfer coefficient value [8,9]. Recent experimental studies prove that this effect is mainly due to turbulence intensity even if integral scale has a significant effect on the distribution of the transfer coefficient at the solid surface [16].

The effect of turbulence intensity can be described through the dimensionless number $\mathrm{Tu} R e^{m}$ which leads to the general relation:

$N u=A R e^{n}\left(1+B \mathrm{Tu} R e^{m}\right)$

In this relation $A R e^{n}$ is the value of the transfer coefficient which is obtained for a free-stream turbulence intensity close to $0 \%$. The structure of relation (2) can be demonstrated theoretically assuming that the scale governing the effect of turbulence is the thickness of the boundary layer [17]. This assumption is consistent with the fact that the effect of integral scale is less as compared to the effect of Tu. Except in very few special situations: $m>0$, that is the effect of Tu is generally the most important of all when product size and air velocity are greater [18]. Parameters $A, n, B$, $m$ of relation (2) are given for some products of various shapes, size and orientation relatively to the flow in Table 1. Examples of the effect of turbulence intensity and product orientation are given in Fig. 1.

For a product of given size, potential variation of transfer coefficient value is mainly dependent on airflow properties (velocity and to a lesser extent turbulence) and less affected by product shape, and direction into the flow. Moreover in practical situations flow direction and turbulence intensity are generally not accurately known. In chillers turbulence intensity can vary from 22 to $60 \%$ while it is generally smaller $(17-19 \%)$ in storage rooms or in dryers [19]. Assuming any flow direction and a turbulence intensity of 15-20\% leads generally to errors on transfer coefficient values which are less than $30 \%$. This has already been shown for short cylinders [18] and is illustrated in Table 2 for two large cylinders. This uncertainty is most often acceptable for calculations of core temperature during chilling. However, that cannot be taken as a universal rule, especially for product of big dimensions and complex shapes. Table 2 illustrates the case of an engineer who wants to determine transfer coefficient 
Table 1

Parameters $A, n, B$ and $m$ of relation (2) for single product of different shapes, dimensions and directions into the flow

\begin{tabular}{|c|c|c|c|c|c|c|}
\hline Product shape & $H / D$ & Angle $\left({ }^{\circ}\right)$ & $A$ & $n$ & $B$ & $m$ \\
\hline \multirow[t]{12}{*}{ Circular cylinder } & 6.00 & 0 & 0.31 & 0.62 & 0.900 & 0.04 \\
\hline & 3.00 & 90 & 0.63 & 0.50 & 0.017 & 0.50 \\
\hline & 1.20 & 90 & 0.35 & 0.57 & 0.730 & 0.10 \\
\hline & 1.20 & 0 & 0.24 & 0.60 & 1.050 & 0.05 \\
\hline & 0.50 & 90 & 0.33 & 0.59 & 0.960 & 0.04 \\
\hline & 0.50 & 70 & 0.36 & 0.59 & 0.820 & 0.02 \\
\hline & 0.50 & 45 & 0.49 & 0.54 & 0.890 & 0.07 \\
\hline & 0.50 & 0 & 0.55 & 0.52 & 1.000 & 0.08 \\
\hline & 0.25 & 90 & 0.24 & 0.64 & 1.140 & -0.02 \\
\hline & 0.25 & 45 & 0.55 & 0.53 & 0.630 & 0.11 \\
\hline & 0.25 & 20 & 0.45 & 0.54 & 0.560 & 0.15 \\
\hline & 0.25 & 0 & 0.69 & 0.50 & 0.890 & 0.10 \\
\hline Elliptical cylinder $(r=4)$ & 3.00 & 90 & 0.67 & 0.50 & 0.017 & 0.50 \\
\hline Truncated cone & 1.00 & 90 & 0.24 & 0.60 & 1.040 & 0.05 \\
\hline Irregular truncated cone & 1.00 & 90 & 0.63 & 0.51 & 0.130 & 0.24 \\
\hline Cone & 1.00 & 90 & 0.34 & 0.56 & 3.960 & -0.11 \\
\hline Cone & 1.00 & 0 & 0.50 & 0.50 & 0.870 & 0.09 \\
\hline Square bar & 2.00 & 90 & 0.26 & 0.58 & 2.950 & -0.01 \\
\hline Bricks $(0.14 \times 0.08 \times 0.22)$ & 0.36 & variable & 0.245 & 0.50 & 0.088 & 0.5 \\
\hline \multicolumn{7}{|l|}{ Pork hindquarter } \\
\hline$L_{\mathrm{car}}=0.67 \mathrm{~m}$ & & 0 & 0.10 & 0.73 & 0.990 & 0.05 \\
\hline \multicolumn{7}{|l|}{$\mathrm{Tu} \leq 8 \%$} \\
\hline \multicolumn{7}{|l|}{ Lamb carcass } \\
\hline Loin & & 0 & 0.26 & 0.67 & 0 & 1 \\
\hline \multicolumn{7}{|l|}{$L_{\mathrm{car}}=0.61 \mathrm{~m}$} \\
\hline \multicolumn{7}{|l|}{ Beef carcass } \\
\hline$L_{\mathrm{car}}=2.6 \mathrm{~m}$ & & 0 & 0.076 & 0.77 & 0 & 1 \\
\hline \multicolumn{7}{|l|}{$\mathrm{Tu}=2.5 \%$} \\
\hline \multicolumn{7}{|l|}{ Beef carcass } \\
\hline$L_{\mathrm{car}}=2.6 \mathrm{~m}$ & & 0 & 0.0074 & 1.00 & 0 & 1 \\
\hline $\mathrm{Tu}>20 \%$ & & & & & & \\
\hline
\end{tabular}

The angle $90^{\circ}$ is the cross-flow direction and $0^{\circ}$ the parallel-flow direction $[8,9,15,18,25,26]$.

values around carcasses of pork, lamb and beef using most recent correlations in the literature (i.e. those in Table 1). Values obtained on the loin of a lamb carcass and a pork hindquarter for $\mathrm{Tu}=8-10 \%$ are close to each other whatever be the air velocity conditions (Table 2). On the contrary, transfer coefficient values can be very different for beef carcasses and for cylinders subjected to high velocity and turbulent airflows which can be encountered during very fast chilling. Transfer coefficient value on the longer cylinder in parallel-flow is half as much as on the shorter cylinder in cross-flow for $\mathrm{Tu}=40 \%$ and $U=5.0 \mathrm{~m} \mathrm{~s}^{-1}$ (Table 2). Transfer coefficient value given for beef carcass is even greater. Thus in this case differences in product shape or Tu greatly affect transfer coefficient values and thus temperature predictions.

Thus engineers have always to do their own preliminary sensitivity analysis and cannot rely on general considerations. Correlations on solid shapes/dimensions which are similar to the product under study will inform them if an accurate knowledge of turbulence intensity and flow direction is required. If no laser or hot wire anemometer is available, or usable, flow direction and turbulence intensity can be assessed by comparing heat transfer coefficients measured around cylinders under the studied conditions to the values issued from Table 1. Table 2 proves that work has still to be done to determine average transfer coefficients under complex practical situations.

When air velocity is very low, mixed convection occurs, i.e. forced and free convection are both involved in the heat exchange. The air velocity which separates forced from mixed convection depends on the difference of temperature between the surface of the product and the air and can be determined from the ratio of the Grashof number to the square of the Reynolds number. The velocity limit which makes the transition is lower than $0.2 \mathrm{~m} \mathrm{~s}^{-1}$ for products of moderate size and differences in temperature are less than $20{ }^{\circ} \mathrm{C}$. Little information is given in the literature to determine heat transfer coefficients under mixed convection situations. The easiest way is to assume a linear relationship between the coefficient values determined for free convection conditions and the first value obtained for forced convection (Fig. 2, [20]). 


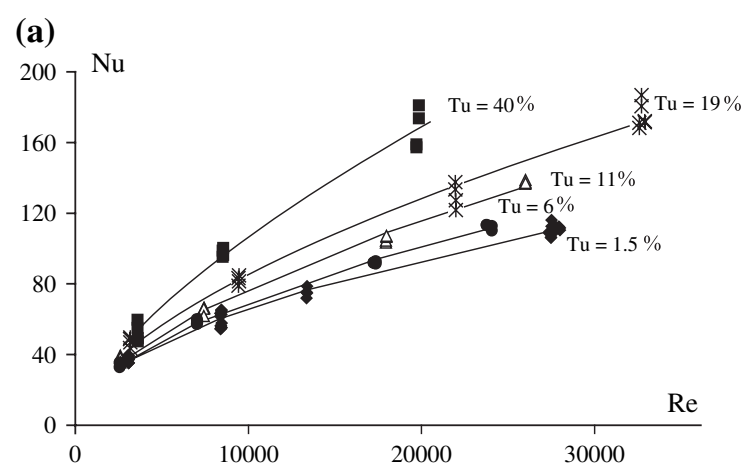

(b)

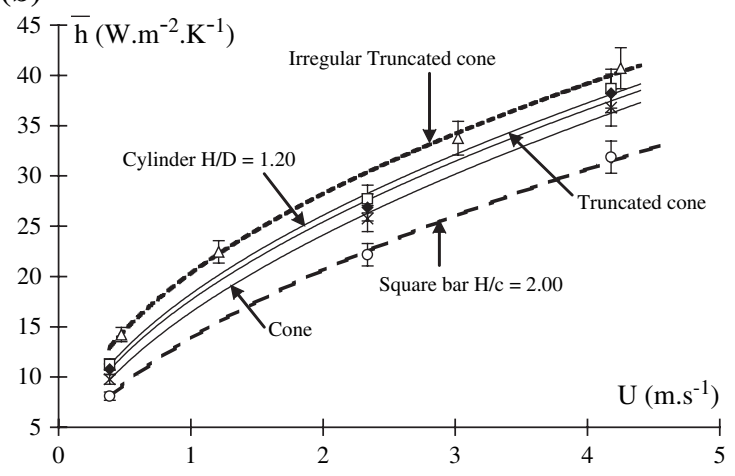

(c)

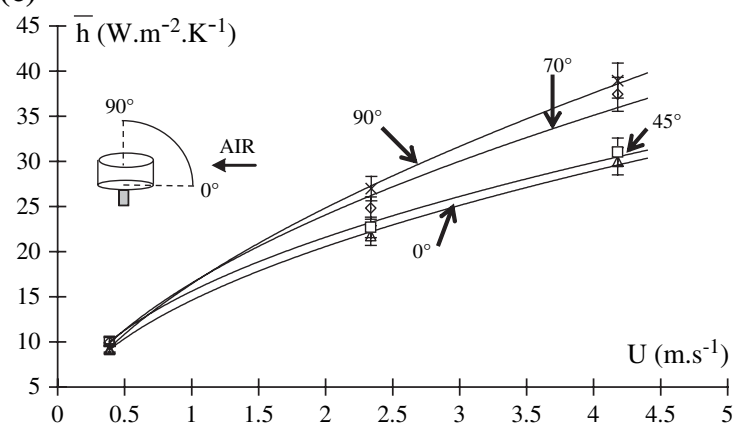

Fig. 1. Effect of different factors on the average heat transfer coefficient value: (a) effect of air velocity and free-stream turbulence intensity for a circular cylinder cross-flow [8]; (b) effect of body shape, $\mathrm{Tu}=1 \%$ [18]; (c) effect of cylinder slope for a short circular cylinder $H / D=0.5, \mathrm{Tu}=1 \%[18]$.

\subsection{Arrangements of products}

Most often in industrial plants, products are very close to each other and transfer coefficients cannot be determined using correlations obtained around single solids.

Heat transfer coefficients have been determined in heat exchangers in which tubes of great height are regularly arranged. Transfer coefficient values depend on the distances: $L, T$ between tubes in the flow and cross-flow direction, respectively. Under the same free-stream conditions,
Table 2

Average heat transfer coefficient value $\left(\mathrm{W} \mathrm{m}^{-2} \mathrm{~K}^{-1}\right)$ calculated from Eq. (2) and parameters of Table 1 under different air velocity and free-stream turbulence intensity conditions

\begin{tabular}{lrrrrr}
\hline Product shape/direction $/\left(L_{\mathrm{car}}\right)$ & $\mathrm{Tu}(\%)$ & \multicolumn{4}{c}{ Air velocity $\left(\mathrm{m} \mathrm{s}^{-1}\right)$} \\
\cline { 2 - 6 } & & $\mathbf{0 . 2}$ & $\mathbf{0 . 5}$ & $\mathbf{1 . 0}$ & $\mathbf{5 . 0}$ \\
\hline Circular cylinder $^{\circ}$ & 5 & 2.1 & 3.7 & 5.6 & 15.4 \\
$H / D=6.0$ & 10 & 2.6 & 3.9 & 6.0 & 16.5 \\
$L_{\text {car }}=2.6 \mathrm{~m}$ & $\mathbf{1 5}$ & $\mathbf{2 . 3}$ & $\mathbf{4 . 2}$ & $\mathbf{6 . 4}$ & $\mathbf{1 7 . 6}$ \\
& $\mathbf{2 0}$ & $\mathbf{2 . 4}$ & $\mathbf{4 . 4}$ & $\mathbf{6 . 8}$ & $\mathbf{1 8 . 7}$ \\
& 30 & 2.7 & 4.8 & $\mathbf{7 . 5}$ & $\mathbf{2 1 . 0}$ \\
& 40 & 3.0 & 5.3 & $\mathbf{8 . 3}$ & $\mathbf{2 3 . 2}$ \\
Circular cylinder $90^{\circ}$ & 5 & 1.3 & 2.2 & 3.4 & 10.2 \\
$H / D=3.0$ & 10 & 1.5 & 2.7 & 4.3 & 14.7 \\
$L_{\text {car }}=2.6 \mathrm{~m}$ & $\mathbf{1 5}$ & $\mathbf{1 . 6}$ & $\mathbf{3 . 1}$ & $\mathbf{5 . 3}$ & $\mathbf{1 9 . 3}$ \\
& $\mathbf{2 0}$ & $\mathbf{1 . 8}$ & $\mathbf{3 . 6}$ & $\mathbf{6 . 2}$ & $\mathbf{2 3 . 8}$ \\
& 30 & 2.2 & 4.5 & $\mathbf{8 . 0}$ & $\mathbf{3 3 . 0}$ \\
& 40 & 2.6 & 5.4 & $\mathbf{9 . 8}$ & $\mathbf{4 2 . 0}$ \\
Beef carcass $0^{\circ}$ & 2.5 & 2.3 & 4.6 & $\mathbf{7 . 8}$ & $\mathbf{2 7 . 0}$ \\
$L_{\text {car }}=2.6 \mathrm{~m}$ & & & & & \\
Beef carcass $0^{\circ}$ & $>20$ & 2.4 & 6.0 & $\mathbf{1 2 . 0}$ & $\mathbf{6 0 . 0}$ \\
$L_{\text {car }}=2.6 \mathrm{~m}$ & & & & & \\
Pork hindquarter $0^{\circ}$ & 10 & 3.1 & 6.1 & 10.0 & 32.0
\end{tabular}

$L_{\text {car }}=0.67 \mathrm{~m}$

Lamb carcass (loin) $0^{\circ}$

$\begin{array}{llll}\text { About } 8 \quad 4.4 & 8.2 & 13.0 \quad 38.0\end{array}$

$L_{\text {car }}=0.61 \mathrm{~m}$

The two cylinders and the beef carcass have the same characteristic length of $2.6 \mathrm{~m}$. The characteristic lengths of the lamb carcass and of the pork hindquarter are smaller and close to each other. Bold figures are those discussed in the text.

transfer coefficient values are greater in these arrangements than around a single tube because of: (1) the increase of air velocity due to the diminution of the flow section and (2) the increase of turbulence due to wakes of upstream tubes. Transfer coefficients in heat exchangers can be determined from the classical correlation Nusselt as a function of the Reynolds if the free-stream air velocity $U$ is replaced by the maximum air velocity $U_{\max }$ inside the arrangement:

$N u=A R e^{n}$

$U_{\max }=\frac{T / D}{(T / D-1)} U$

where $D$ is the diameter of tubes. $A$ and $n$ values from different authors are given in Table 3 .

Food products are not long tubes but short objects lying on supports and arranged in more or less opened packages. To take into account these factors, transfer coefficients have been measured around short cylinders while varying upstream flow properties $(U, \mathrm{Tu})$, arrangement and distances between cylinders. Perforated plates have also been added upstream to simulate the effect of open packages and air velocity has been measured between cylinders [21]. 


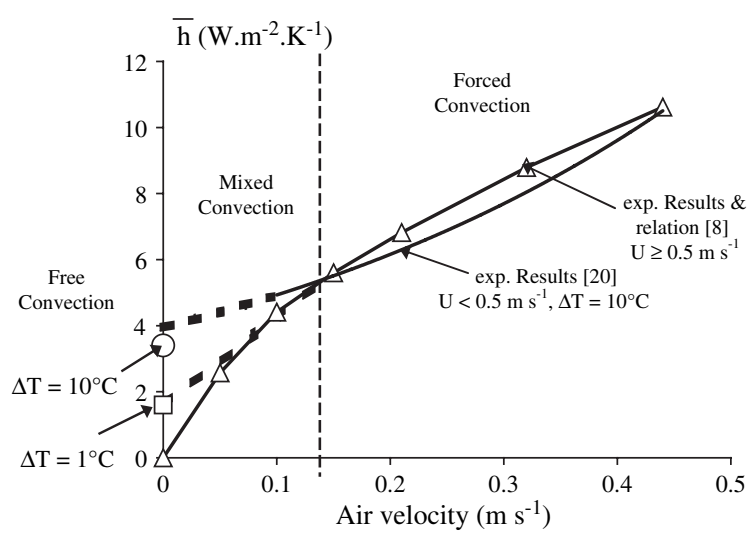

Fig. 2. Average heat transfer coefficient as a function of air velocity for $0 \leq U<0.5 \mathrm{~m} \mathrm{~s}^{-1}$. The sample is a circular cylinder cross-flow for which the height to diameter ratio is 0.5 . Line with triangles is a correlation obtained for $U \geq 0.5 \mathrm{~m} \mathrm{~s}^{-1}$ and extended down to $U=0 \mathrm{~m} \mathrm{~s}^{-1}$ [8]. Black line (no symbols) describes experimental results obtained for $0.2 \leq U \leq 0.5 \mathrm{~m} \mathrm{~s}^{-1}$ [20]. Circle and square points are $h$ values calculated from a correlation given for pure free-stream conditions [14].

Distribution of transfer coefficient is given as a function of the number of the row in Fig. 3 in the case of: $T / D=$ $L / D=2.2, U=1.4 \mathrm{~m} \mathrm{~s}^{-1}$ and for two free-stream turbulence intensities: $\mathrm{Tu}=1 \%$ and $\mathrm{Tu}=53 \%$. When the upstream flow is slightly turbulent, heat transfer coefficient increases from row 1 to row 2 then stabilises or tends to decrease slowly. When upstream turbulence intensity increases to $53 \%$ transfer coefficient increases in each row compared to the value measured at the same location value for $\mathrm{Tu}=1 \%$. This increase is more important in the first row, where the value of $h$ becomes close to that on the cylinder of the second row. The effect of an added perforated plate is complex depending on the way turbulence is generated and on whether the cylinder is in front of a hole or in front of a wall.

Table 3

Parameters $A, n$ used to calculate the heat transfer coefficient value in heat exchangers (3) as a function of the maximum air velocity between cylinders (4) and depending on the distance between tubes

\begin{tabular}{llll}
\hline Authors & $T / D$ and $L / D$ & $A$ & $n$ \\
\hline Zukauskas & $1.3 \leq T / D, L / D \leq 2.6$ & 0.24 & 0.63 \\
Grimison & $T / D=L / D=1.25$ & 0.35 & 0.59 \\
& $T / D=L / D=1.5$ & 0.25 & 0.62 \\
& $T / D=L / D=2.0$ & 0.23 & 0.63 \\
Saito and Kishinami & $T / D=L / D=1.7$ & 0.26 & 0.62 \\
& $T / D=L / D=2.0$ & 0.24 & 0.63 \\
Stephan and Traub & $T / D=L / D=2.3$ & 0.22 & 0.64 \\
& $T / D=L / D=1.5$ & $0.14 \mathrm{Tu}^{0.103}$ & 0.67 \\
& & $0.076 \mathrm{Tu}^{0.103 / N}$ & 0.74
\end{tabular}

Studies have been reviewed in [21].
Food arrangements include a great numbers of rows subjected to surrounding flows which are already turbulent. Thus great differences in transfer coefficient cannot be explained by local variations of turbulence intensity but are mainly due to local differences in air velocity. In industrial plants, airflow is not channelled as in heat exchangers. Air circulation in the plant interacts with food arrangements to lead to a flow path which is different in each arrangement. Parts of a food arrangement can be subjected to very high air velocities while in other parts air is stagnant. Results obtained in heat exchangers are of no use in this situation. Local air velocities inside the arrangement have to be determined and used to calculate the local transfer coefficient around each product. Heat transfer coefficients in an arrangement of short cylinders can be determined for $1.1 \leq T / D, L / D \leq 2.2$ using the local air velocity calculated/measured in the arrangement and relation (3). $A$ and $n$ are $1.24,0.50$ for the second row of cylinders and 0.66 , 0.56 for downstream rows, respectively [21]. Correlations which describe heat transfer coefficients inside a packed bed of spheres can be found for free convection in $[4,5]$ and for forced convection [22,23].

\section{Distribution of transfer coefficient at the surface of a product - calculations using CFD models}

\subsection{Experimental distribution at the surface of a food product}

A lot of food products or food packages have shapes which are in 2D close to ellipses, circles, plates, squares or rectangles. Distributions of transfer coefficients on these 2D shapes subjected to laminar airflow depend on Reynolds values and are quite well known [13-15]. On a flat plate, heat transfer coefficient value is 30 times greater at $1 \mathrm{~mm}$ from the stagnation point than $0.1 \mathrm{~m}$ downstream. In practice this ratio depends on the thickness and the length of the plate and on the shape of its leading edge. On ellipses, at moderate Reynolds number, the ratio of the stagnation point heat transfer to its average value increases with the ratio $r$ of the major to the minor axis of the ellipse. This transfer coefficient ratio is of about 2.4 and 4.5 for $r$ equal to 3 and 4 , respectively. Distribution of transfer coefficient is complicated by boundary layer separations due to surface singularities (corners) or changes in curvature. On a circular cylinder for $R e<90,000$ the ratio $N u / R e^{0.5}$ which is 0.95 at the stagnation point decreases to about 0.4 at separation $\left(\theta=85-90^{\circ}\right)$ and then stabilises of increases in the wake (Fig. 4a). This increase in the wake depends on Reynolds number. Phenomena are similar on elliptical cylinders and on circular cylinders (Fig. 4b). Free-stream turbulence intensity and integral scales can modify the distribution of the transfer coefficient around 2D objects but it keeps its general feature for moderate Reynolds number $[8,16]$.

In practice, shape of food products or food packages is not that of an infinite elliptical or circular cylinder or of 


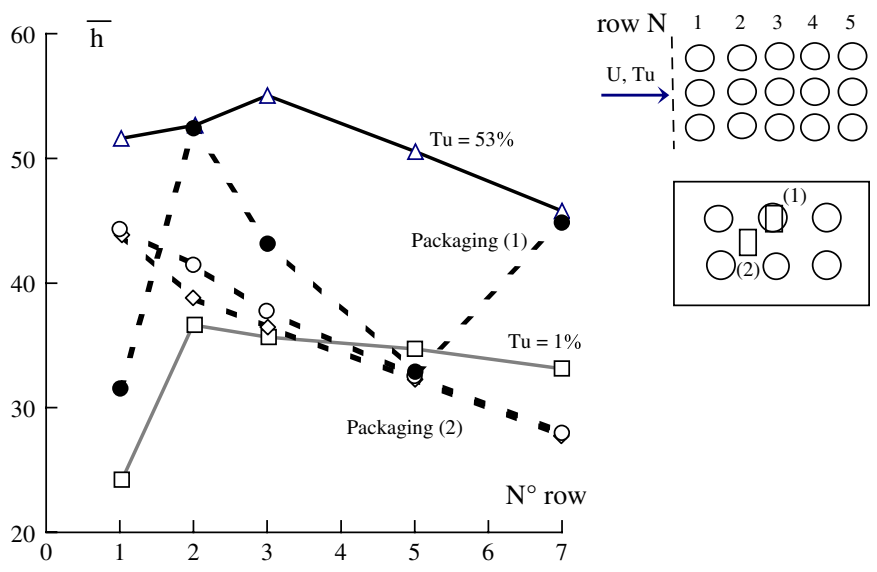

Fig. 3. Heat transfer coefficient in a regular arrangement of short circular cylinders $(T / D=L / D=2.2)$ as a function of: the row number, the free-stream turbulence intensity and the position in relation to packaging holes, $U=1.4 \mathrm{~m} \mathrm{~s}^{-1}[21]$.

a rectangular bar but that of a short cylinder or of a parallelepiped. Heat transfer coefficient has been mapped out at the surface of two short circular cylinders with height to diameter ratios of 3.0 and 0.3 , respectively [24]. Whatever the proximity to the top end of the cylinder, distribution profiles on the sides of the cylinder keep globally the well-known

(a)

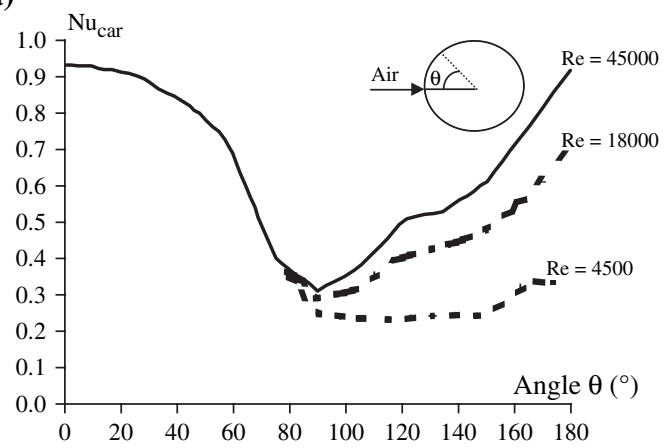

(b)

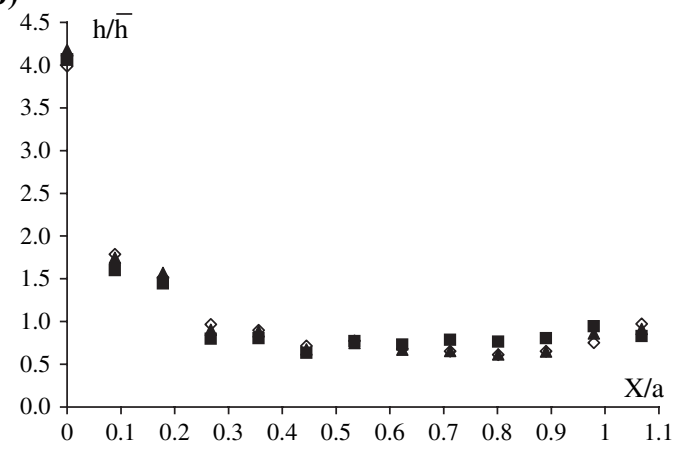

Fig. 4. Distribution of the transfer coefficient at the surface of: (a) an infinite circular cylinder cross-flow for three different Reynolds numbers; (b) at the surface of an elliptical cylinder $r=4, a=0.1 \mathrm{~m}$ which was subjected to airflow velocities smaller than $1.0 \mathrm{~m} \mathrm{~s}^{-1}$ [8]. features of the 2D profile existing on the "infinite cylinder". However, location of separation point and variations in the wake depend on the main flow velocity and turbulence intensity and on the proximity of the upstream corners. For the cylinder $H / D=3$ difference of profile in the wake due to the distance from ends increases with the Reynolds number at low free-stream turbulence intensity (Fig. 5a). It disappears at much higher free-stream turbulence intensity due to the inhibition of the development of the separationreattachment vortices by main flow turbulence (Fig. 5b). On the side of the cylinder $H / D=0.3$, very close vicinity of the end corners tends to move the separation point downstream.

Circular map out obtained on the end of the cylinder $H / D=3.0$ for $R e=9000$ and $\mathrm{Tu}=1.5 \%$ is shown in Fig. 6a. The transfer coefficient value, which is great on the upstream rim (upstream edge of the circle) decreases sharply downstream to a minimum and then increases again. The lines of equal coefficient value take on a crescent shape. Downstream from the crescent-shape area is an area where the lines of equal coefficient value have curious "bracketshaped" features. Visualisation of the flow pattern on the top end of the cylinder is given in Fig. 6b. The flow pattern enables a better comprehension of some features of the coefficient map out especially the crescent-shape and the bracket-shape areas.

Local values of the transfer coefficients were measured around the 3D complex shape of a pork hindquarter for $U<1.0 \mathrm{~m} \mathrm{~s}^{-1}$ and $1 \% \leq \mathrm{Tu} \leq 30 \%$. They ranged from $0.6 \bar{h}$ to $1.4 \bar{h}$ with a standard deviation of $0.2 \bar{h}$. Unlike for cylinders, coefficients could not be mapped out on a pork hindquarter. Distributions were irregular and impossible to relate to the boundary flow pattern, which was not known. Under the range of studied conditions, the effect of an inversion of the flow direction on the distribution of the transfer coefficients was greater than the effect of a variation of air velocity or turbulence intensity. 
(a)

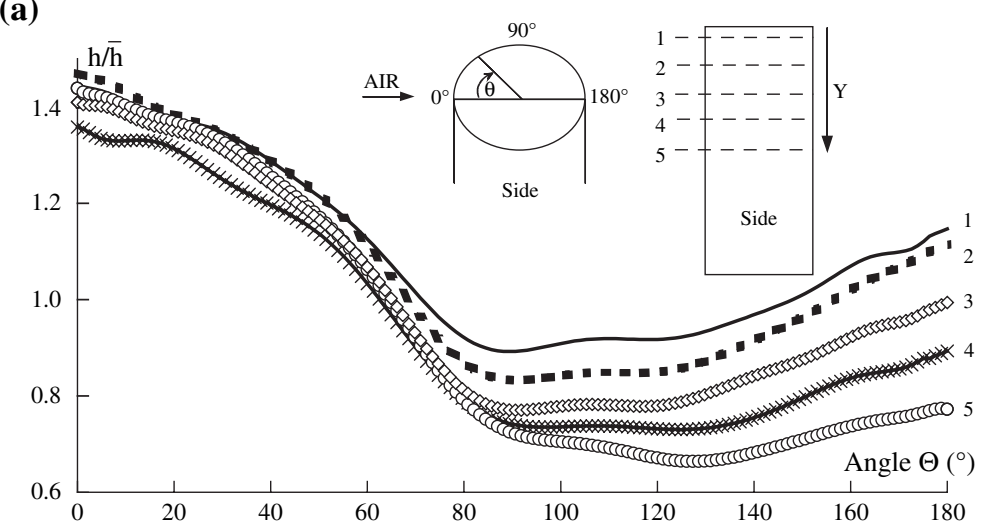

(b)

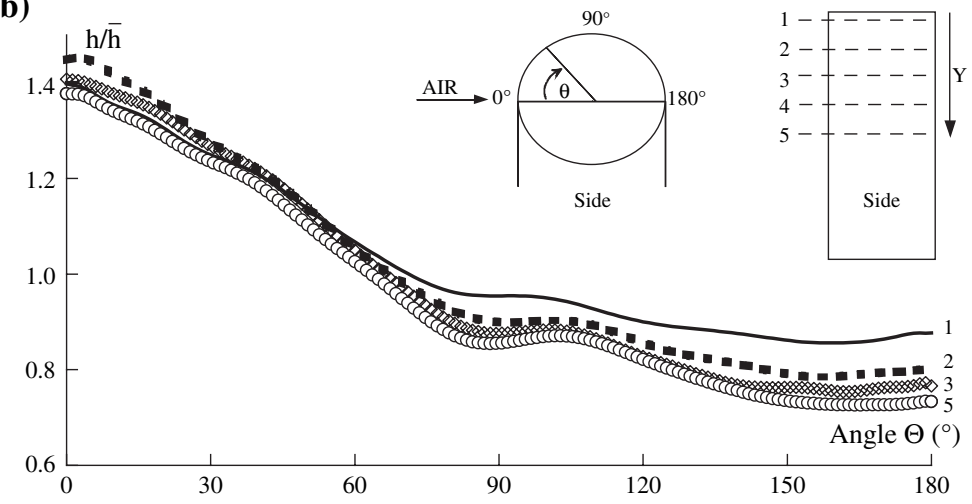

Fig. 5. Heat transfer coefficient distribution in the free-stream direction at different distances from the top end of a cylinder $H / D=3.0$ and $0.10 \mathrm{~m}$ in diameter in cross-flow: (a) $U=3.85 \mathrm{~m} \mathrm{~s}^{-1}, \mathrm{Tu}=1.5 \%$; (b) $U=4.45 \mathrm{~m} \mathrm{~s}^{-1}$, $\mathrm{Tu}=28.0 \%$ [24].

Local values of heat transfer coefficient have been measured around a lamb and a beef carcass [25,26]. Measurements were performed at four positions on the lamb carcass for air velocity and turbulence intensity ranging from 0.5 to $8.0 \mathrm{~m} \mathrm{~s}^{-1}$ and 1 to $8 \%$, respectively. Transfer coefficient was 2-5-fold higher at one position (the loin) relatively to the others. The effect of turbulence intensity was in this case less important than that of sensor location. Measurements were repeated using the same method at 11 locations on one side of a $2.6 \mathrm{~m}$ beef carcass for air velocities ranging from 0.5 to $5.5 \mathrm{~m} \mathrm{~s}^{-1}$. Two levels of turbulent intensity were examined, $2.5 \%$ and approximately $20 \%$. The highest turbulence intensity level was obtained using a promoter which introduced a variation of Tu in the flow direction from about $40 \%$ upstream to about $10 \%$ downstream of the carcass. Turbulence was also heterogeneous in cross-flow direction and differences in average velocity were likely to exist due to blockage effects. These heterogeneous conditions are probably close to what could be observed in industrial plants around carcasses. A marked increase of Tu was observed at all but one (tenderloin) sensor locations when the turbulence promoter was introduced. Difference due to sensor location was important whatever the flow conditions and tends to increase with air velocity and turbulence intensity. The values of $A$ and $n$ in relation (5) are given as a function of sensor location in Table 4.

$h=A U^{n}$

Heat transfer coefficient at tenderloin was found to be unusually low which can raise problems of chilling for this valuable muscle.

Previous works prove that local differences of transfer coefficients, due to the development of the boundary flow, are potentially as important on bodies of complex shapes as on circular or elliptical cylinders. These differences can be modified by the local heterogeneity of air velocity and turbulence intensity which exists in industrial plants.

Distribution of transfer coefficient at the surface of one cylinder located in an arrangement is complex and depends on the flow regime. Three types of flow regime are distinguished by Zdravkovich (Fig. 7a, [27]): $\left(\mathrm{S}_{1}\right)$ $1<L / D<1.2-1.8$, the wake issued from the upstream cylinder does not reattach on the second cylinder or eventually far downstream; $\left(\mathrm{S}_{2}\right) 1.2-1.8<L / D<3.4-3.8$, the mixing layer issued from the upstream cylinder reattaches on the upstream part of the second cylinder; $\left(\mathrm{S}_{3}\right)$ 


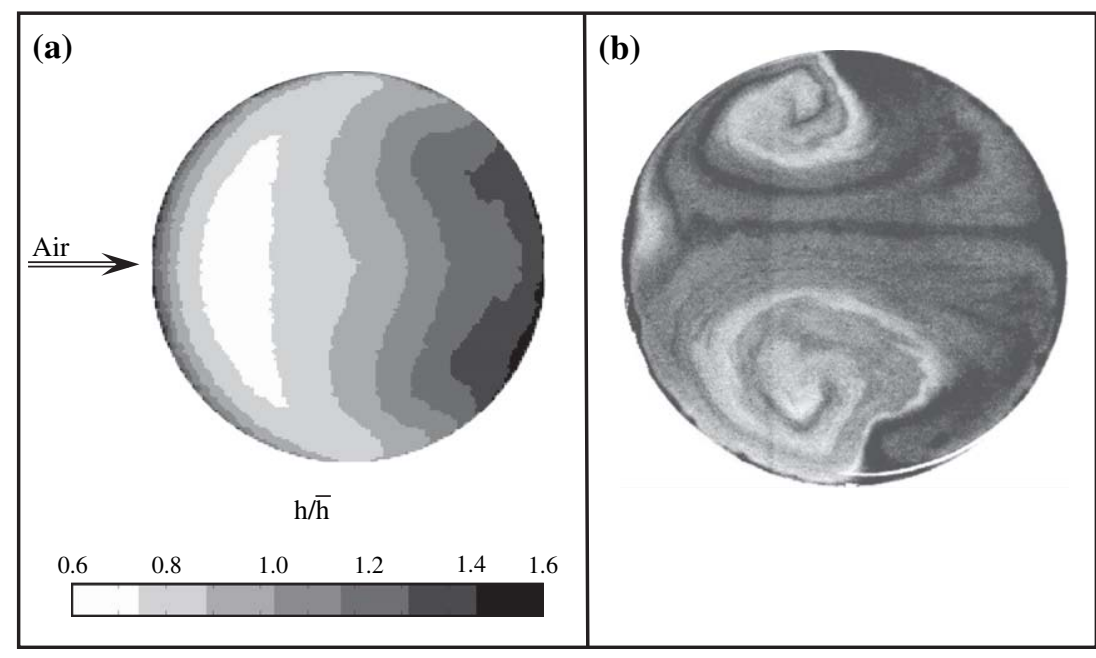

Fig. 6. (a) Map out of the heat transfer coefficient on the ends of the cylinder $H / D=3.0$ and $0.10 \mathrm{~m}$ in diameter, $U=3.85 \mathrm{~m} \mathrm{~s}{ }^{-1}$, Tu $=1.5 \%$; (b) flow visualisation on the ends of the cylinder under similar frees-stream conditions [24].

$3.4-3.8<L / D<6.0$, a real wake exists in between the two cylinders. Fig. $7 \mathrm{~b}$ presents the effect of the change of the flow regimes $S_{1}-S_{2}$ on the distribution of the transfer coefficient at the surface of four cylinders in line (for more details see [27]).

\subsection{Calculations of heat transfer coefficient using CFD models}

Local values of heat transfer coefficient can be calculated using CFD models. Calculated values and distribution of heat transfer coefficient around rectangular packaging

\section{Table 4}

Parameters $A$ and $n$ of relation (5) used to determine the local variation of the heat transfer coefficient at the surface of a beef carcass under two types of free-stream turbulence intensity conditions: Tu equal to $2 \%$ or higher than $20 \%$ [26]

\begin{tabular}{lccccc}
\hline $\begin{array}{l}\text { Location at the } \\
\text { surface of the } \\
\text { beef carcass }\end{array}$ & $\begin{array}{l}\text { Without turbulence } \\
\text { promotion } \\
(\mathrm{Tu}=2 \%)\end{array}$ & & \multicolumn{2}{l}{$\begin{array}{l}\text { With turbulence } \\
\text { promotion (average } \\
\text { Tu about 20\%) }\end{array}$} \\
\cline { 2 - 3 } \cline { 5 - 6 } & $A$ & $n$ & & $A$ & $n$ \\
\hline Outside leg & 8.7 & 0.84 & & 21.0 & 1.1 \\
Inside leg & & & & 24.5 & 1.0 \\
Rump & 10.1 & 0.71 & & 17.5 & 0.93 \\
Loin & 12.5 & 0.68 & & 16.4 & 0.81 \\
Tib eye & 10 & 0.78 & & 3.1 & 0.80 \\
Blade & 10.8 & 0.79 & & 16.0 & 0.72 \\
Shoulder & 6.6 & 1.1 & & 12.1 & 1.0 \\
Neck & 9 & 0.86 & & 13.1 & 0.88 \\
Tenderloin & & & & 2.2 & 2.0 \\
13th Rib & 8.2 & 0.78 & 8.6 & 0.99 \\
14th Rib & 11.6 & 0.66 & 12.1 & 0.76 \\
\hline
\end{tabular}

$(250 \leq R e \leq 10,000)$ and cylinders ( $R e<1000$, Fig. 8) were found to be in good agreement with experimental results under low air velocity and nearly laminar airflow conditions $[15,28]$. Predictions are more difficult for higher air velocities and high turbulent flows.

The effect of free-stream turbulence on transfer coefficient values is complex. When turbulence structures approach the wall they deform and turbulence becomes highly anisotropic. This anisotropic turbulence interacts/ penetrates the viscous boundary layer. Modification of boundary layer under free-stream turbulence has been partially studied experimentally on flat plates where the layer is thick enough to permit measurements. Interactions between free-stream turbulence and wake vortices are even more complex than for boundary layers and lesser known.

$k-\varepsilon$ models have been developed more than 30 years ago to describe nearly-isotropic turbulences. $k-\varepsilon$ models are valid at high turbulent Reynolds numbers (far from walls and not in shear-flow regions). They have been corrected more recently to better account for turbulence anisotropy in re-circulating flows regions. $k-\varepsilon$ models are not adapted in the vicinity of the wall and thus often associated in this region to the "law of the wall", a relation based on the structure of the fully turbulent boundary layer which can develop on a flat plate. This approach is strictly valid for very long plates and high air velocities which is seldom the case during the treatment of food products. The law of the wall can be replaced by low turbulent Reynolds number functions which take into account the damping of turbulent fluctuations by the viscous boundary layer. However, parameters used in these functions cannot be considered as "universal".

The standard $k-\varepsilon$ model in the free-stream and the two previous near-wall modelling approaches have been used to predict the distribution of heat transfer coefficient in the 
(a)

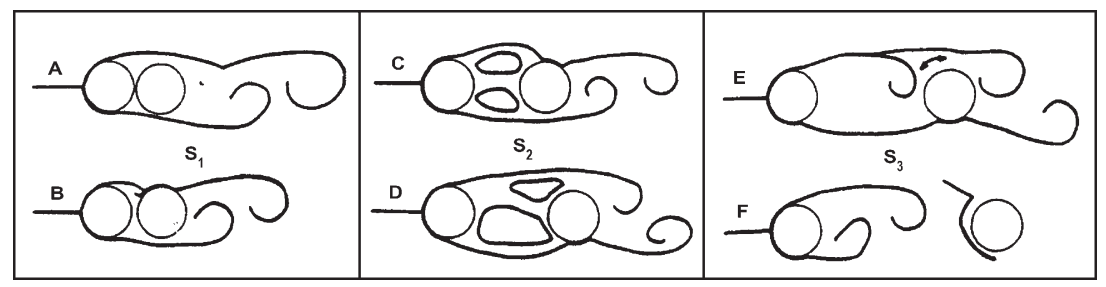

(b)

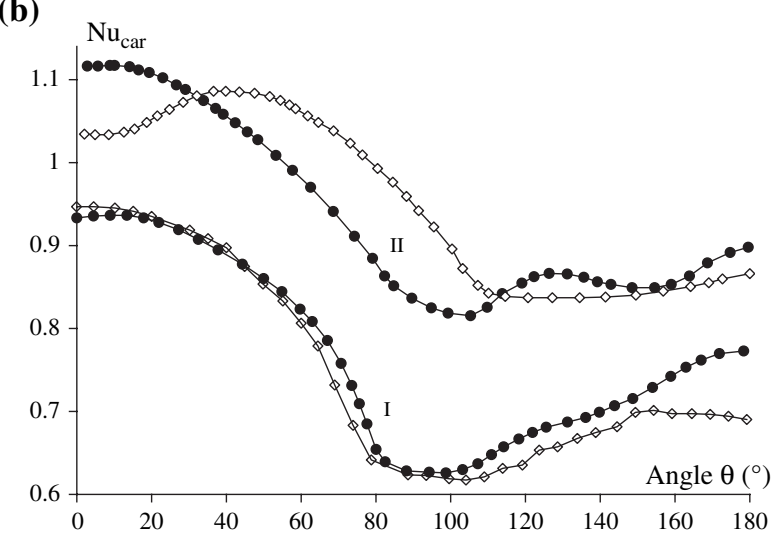

Fig. 7. (a) Classification of the three different flow regimes: $S_{1}, S_{2}, S_{3}$ for two cylinders in line as a function of their distance in the flow direction $L / D$; (b) difference in the heat transfer coefficient distributions on the upstream (I) and downstream (II) cylinders between the regime, $\mathrm{S}_{2}$, white diamond, and the regime $\mathrm{S}_{3}$, black dots. From Kostic and Oka (1972), quoted by [27].

case of rectangular packages subjected to very low turbulent airflows $(250 \leq R e \leq 20,000,[15])$. This approach was generally less efficient than laminar flow modelling and not able to describe transfer coefficient distribution in wakes even when these wakes were strongly turbulent $(R e=20,000)$. CFD calculations were also compared to experimental results for an infinite circular cylinder in cross-flow in the range: $5000 \leq R e \leq 40,000,1.5 \% \leq \mathrm{Tu} \leq 40 \%$ [29]. Whatever the near-wall approach, the calculated transfer coefficient distributions were different from the experimental ones for the greatest free-stream turbulence intensities and air velocities. This disagreement was mainly due to an overproduction of kinetic energy by $k-\varepsilon$ model. Results obtained using the law of the wall were dependent on the numerical cell dimension in the cross-direction near the wall. For the range of cell dimensions chosen to ensure a coherent transfer coefficient distribution, calculated transfer coefficients overestimated experimental results by $37-80 \%$. The prediction capability of low Reynolds number functions was better than that of the law of the wall in the case of highly turbulent flow. Results were independent of the near-wall cell dimension and the average difference between calculated and experimental results was $10 \%$ for all the studied conditions. However, this very satisfactory average result hides great differences depending on inlet flow conditions and a difference of up to $43 \%$ was noticed in one condition. Agreement between calculated and experimental results was improved by fitting the damping parameter of the low Reynolds number function on the thickness of the laminar boundary sublayer (Fig. 9).

The use of an RNG $k-\varepsilon$ model (Renormalisation Group $k-\varepsilon$ model) associated with the law of the wall was recently advanced for the prediction of transfer coefficients under chilling conditions [30]. The studied situation mixed two problems of modelling: (1) the prediction/characterisation of free-stream turbulence under highly anisotropic conditions, and (2) the prediction of boundary flow and transfer coefficients around a body of complex shape. As accurate measurements of surface temperatures and of transfer coefficients were difficult under the studied conditions, general conclusions on models efficiency are difficult to draw from this study.

Calculations of transfer coefficients by low Reynolds functions require very fine meshing close to the wall. This is impossible for big arrangements of food products. In this case transfer coefficients cannot be reliably predicted by CFD models and have to be introduced in codes using correlations. This type of approach was used to study the 2D distribution of temperature inside a pallet of yoghurts during cooling [31]. Similar 3D approach including mass transfer is under development in our laboratory for a pallet of cheeses during maturation.

Large eddy simulation (LES) has been used to investigate the effect of free-stream turbulence on the increase 
(a)

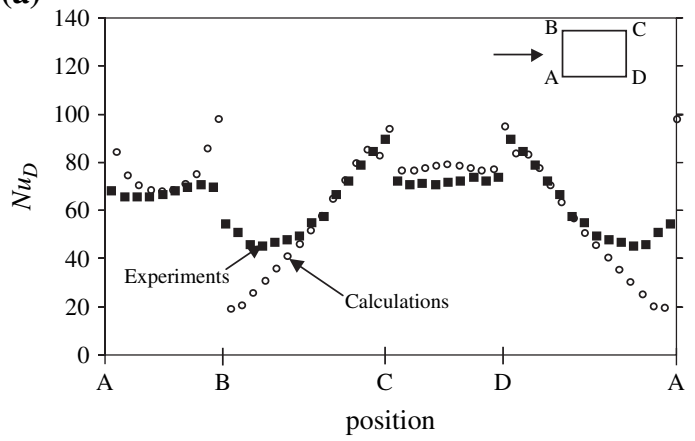

(b)

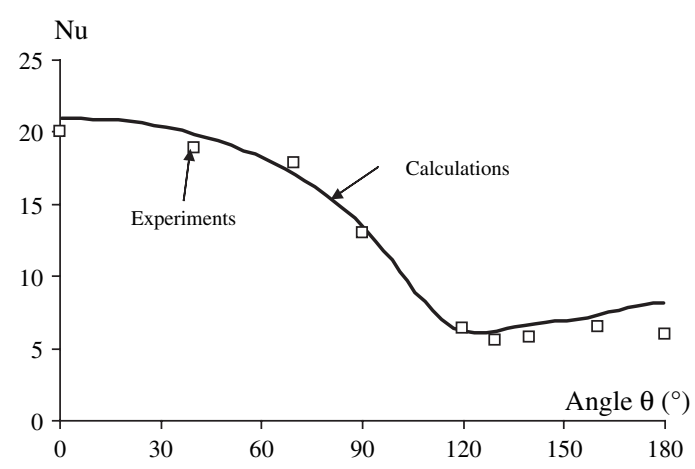

Fig. 8. Comparison between the distribution of the transfer coefficient calculated by CFD models and experimental results: (a) body of rectangular shape, $L / D=1.5, R e=5000$ [15]; (b) infinite circular cylinder cross-flow $R e=500$ [28].

of heat transfer coefficient at the surface of a flat plate [32]. Bypass transition was found to occur at low Reynolds numbers, in the early stage of boundary layer development. Streaks develop in the wall layer which led to the production of turbulence very close to the wall. The turbulence production and the effect of Tu on temperature and velocity profiles have been validated experimentally [33]. These investigations give an idea of the mechanisms which can explain the effect of free-stream turbulence on transfer coefficients and comfort the theoretical structure of relation (2). However, LES results are very sensitive to the characteristics of the inlet turbulent field which have to be fully described. Comparison with experiments requires a perfect experimental knowledge of this turbulent field and a statistical treatment of calculated results on many runs. Thus this approach is yet confined to theoretical studies very different from the practical situations encountered by engineers.

\section{Conclusions - future trends}

Average transfer coefficients on single foods or packages of simple shapes subjected to chilling-storage conditions are now well known. This is especially true for (a)

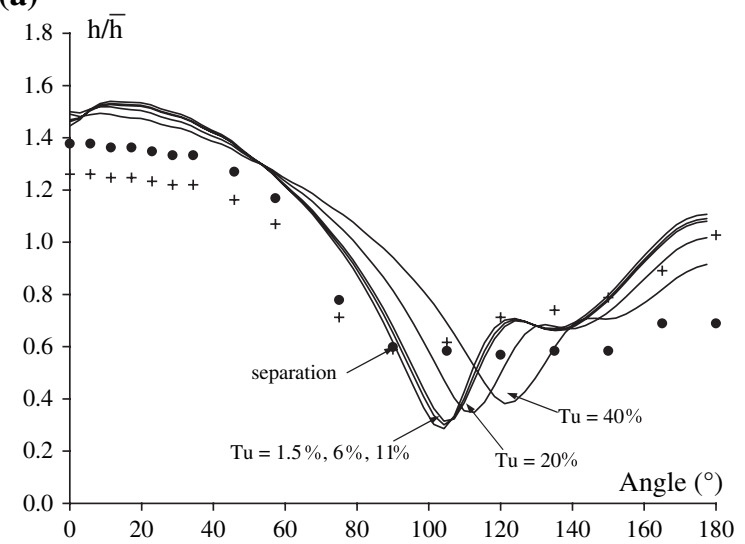

(b)

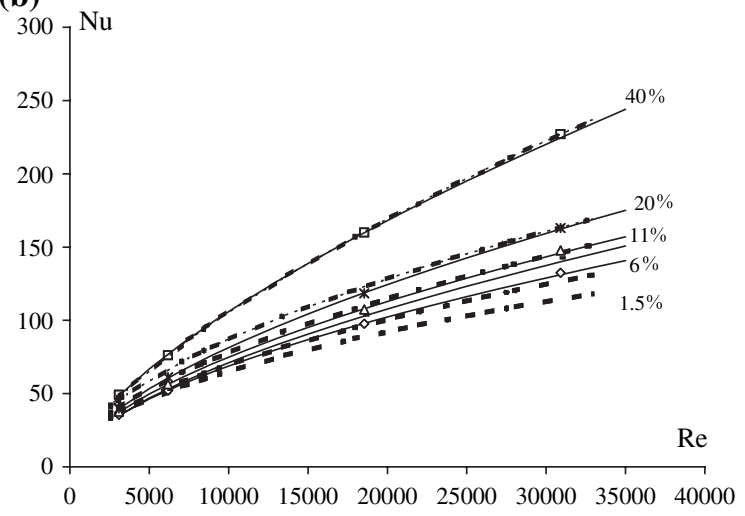

Fig. 9. Comparison between heat transfer coefficients calculated by a $k-\varepsilon$ model associated to a low Reynolds function (symbols, full lines), with experimental results (dashed lines) obtained on an infinite circular cylinder cross-flow: (a) distribution of the transfer coefficient as a function of the free-stream turbulence intensity Tu $(R e=3000)$; (b) average transfer coefficient value as a function of $R e$ and $\mathrm{Tu}$, the damping parameter of the low Reynolds function being dependent on Tu.

cylinders of different heights sloped at different angles in turbulent airflows. Average transfer coefficient values on products of more complex shapes: animal carcasses, part of carcasses, etc. are less well known. As the effect of flow properties is generally more important than that of shape, transfer coefficients can, as a first approximation, be estimated from those of cylinders. However, this approach is not always valid and cumulative effects of shape, dimension, orientation and turbulence can lead to great differences between the estimated and actual transfer coefficients.

In arrangements of short cylinders or spheres (pallets of yoghurts, cheeses, fruits, etc.) variation of transfer coefficient values is mainly due to local variations in air velocity. A preliminary study is needed to characterise the variation of $U$ inside arrangement. Then transfer coefficients shall be 
determined using correlations established as a function of the local values of $U$.

Transfer coefficients can double from one place to another at the surface of the same product. This surface variation can most of the time be neglected when the core temperature of the product is of interest, while it plays an important part in the prediction of temperature heterogeneities, especially at, or close to, the surface of a product (such as specific surface muscles in a carcass). Three-dimensional distributions of heat transfer coefficients have been determined on two short cylinders cross-flow and explained by the structure of the boundary flow. On products of more complex shapes (carcasses), local measurements of transfer coefficients remain difficult and maps of the variations have not yet been obtained due to: (1) the difficulty in generating a constant temperature or constant heat flux on the entire solid surface, (2) the requirement of a complete 3D flux or temperature measurement. New methods to map out heat transfer coefficient around solid of complex shapes will probably rely: (1) on transient measurement of surface temperature by IR cameras or liquid crystals during solid heating or cooling, and (2) data treatments by inverse numerical methods.

Accurate measurement of transfer coefficients will always remain difficult and time consuming especially under complex situations. As CFD codes are now commercially available, direct CFD calculations of transfer coefficients will be more and more the approach chosen by scientists and engineers. The limits of the present $k-\varepsilon$ models associated with near-wall treatments have been discussed in this paper. LES models, up to now confined to theoretical studies, are much more powerful than $k-\varepsilon$ models in predicting flow separation and wake formation. Some simple LES models are already available in commercial codes and in the near future what has happened for the $k-\varepsilon$ models will probably be repeated for LES. Different types of LES models will be implemented in CFD codes and they will be used by scientists and engineers to predict transfer coefficients under more and more complex conditions. However, LES requires very fine meshing and a statistical treatment of results on many runs. Moreover calculated results will depend on the characteristics of the inlet turbulent flow. Thus experimental investigations will still be needed.

\section{References}

[1] B.R. Becker, B.A. Fricke, Heat transfer coefficients for forced-air cooling and freezing of selected foods, International Journal of Refrigeration 27 (2004) 540-551.

[2] I. Dincer, Development of new effective Nusselt-Reynolds correlations for air-cooling of spherical and cylindrical products, International Journal of Heat and Mass Transfer 37 (17) (1994) 2781-2787.

[3] A. Kondjoyan, O. Rouaud, M.S. McCann, M. Havet, A. Foster, M. Swain, J.D. Daudin, Modelling coupled heatwater transfers during a decontamination treatment of the surface of solid food products by a jet of hot air - I. Sensitivity analysis of the model and first validations of product surface temperature under constant air temperature conditions, Journal of Food Engineering 76 (2006) 53-62.

[4] S. Ben Amara, Ecoulement et transferts thermiques en convection naturelle dans les milieux macro-poreux alimentaires Application aux réfrigérateurs ménagers, Thèse de Doctorat de l'Institut National Agronomique Paris, Grignon (France), 2005, 203 pp.

[5] S. Ben Amara, O. Laguerre, D. Flick, Experimental study of convective heat transfer during cooling with low air velocity in a stack of objects, International Journal of Thermal Science 43 (2004) 1213-1221.

[6] A. Kuitche, J.D. Daudin, G. Létang, Modelling of temperature and weight loss kinetics during meat chilling for time variable conditions using an analytical based method I - the model and its sensitivity to certain parameters, Journal of Food Engineering 28 (1) (1996) 55-84.

[7] A. Kondjoyan, J.D. Daudin, Determination of transfer coefficients by psychrometry, International Journal of Heat and Mass Transfer 36 (7) (1993) 1807-1818.

[8] A. Kondjoyan, J.D. Daudin, Effects of free stream turbulence intensity on heat and mass transfers at the surface of a circular cylinder and an elliptical cylinder, axis ratio 4, International Journal of Heat and Mass Transfer 38 (10) (1995) $1735-1749$.

[9] A. Kondjoyan, J.D. Daudin, Heat and mass transfer coefficients at the surface of a pork hindquarter, Journal of Food Engineering 32 (2) (1997) 225-240.

[10] P. Verboven, N. Scheerlinck, J. De Baerdemaeker, B. Nicolaï, Sensitivity of the food centre temperature with respect to air velocity and the turbulence kinetic energy, Journal of Food Engineering 48 (2001) 53-60.

[11] A. Kondjoyan, Optimisation of air-flow conditions during the chilling and storage of carcasses and meat products, Journal of Food Engineering 34 (3) (1997) 243-258.

[12] P.S. Mirade, A. Kondjoyan, J.D. Daudin, Three-dimensional CFD calculations for designing large chillers, Computers and Electronics in Agriculture 34 (2002) 339-367.

[13] H. Schlichting, Boundary Layer Theory, seventh ed. McGrawHill, New York, 1979 (classic textbook reissue series) 814 pp.

[14] N.M. Ozisik, Heat Transfer: A Basic Approach, McGrawHill, New York, 1985, 780 pp.

[15] P. Verboven, B. Nicolaï, N. Scheerlinck, J. De Baerdemaeker, The local surface heat transfer coefficient in thermal food process calculations: a CFD approach, Journal of Food Engineering 33 (1997) 15-35.

[16] F. Peyrin, A. Kondjoyan, Effect of turbulent integral scale on heat transfer around a circular cylinder placed cross to an air flow, Experimental Thermal and Fluid Science 26 (2002) 455-460.

[17] A. Kondjoyan, Echanges de chaleur convectifs air/solide Analyse de l'effet de l'indice de turbulence sur les transferts de chaleur à la paroi, Entropie 233 (2001) 12-19.

[18] L. Ghisalberti, A. Kondjoyan, Convective heat transfer coefficients between air flow and a short cylinder - effect of air velocity and turbulence. Effect of body shape, dimensions and position in the flow, Journal of Food Engineering 42 (1999) 33-44.

[19] J.D. Daudin, A. Kondjoyan, Influence de l'indice de turbulence de l'écoulement sur les procédés de traitement thermique de solides par l'air (Lavoisier), Récents Progrès En Génie Des Procédés 5 (13) (1991) 287-293. 
[20] P.S. Mirade, T. Rougier, A. Kondjoyan, J.D. Daudin, D. Picque, G. Corrieu, Caractérisation expérimentale de l'aéraulique d'un hâloir de fromagerie et des échanges airproduits, Lait 84 (2004) 483-500.

[21] N. Carniol, A. Kondjoyan, J.D. Daudin, G. Alvarez, J.J. Bimbenet, Valeur et répartition des coefficients de transfert dans un ensemble de cylindres de hauteur réduite soumis à un écoulement d'air turbulent, Entropie 227 (2000) 42-52.

[22] G. Alvarez, D. Flick, Analysis of heterogeneous cooling of agricultural products inside bins - Part II: thermal study, Journal of Food Engineering 39 (1999) 239-245.

[23] D. Flick, A. Leslous, G. Alvarez, Modélisation semi-empirique des écoulements et des transferts dans un milieu poreux, International Journal of Refrigeration 26 (2003) 349-359.

[24] L. Ghisalberti, A. Kondjoyan, Complete map out of the heat transfer coefficient at the surface of two circular cylinders $H / D=3.0$ and 0.3 subjected to a cross-flow of air, International Journal of Heat and Mass Transfer 45 (2002) 2597-2609.

[25] M.B. Harris, J.K. Carson, J. Willix, S.J. Lovatt, Local surface heat transfer coefficients on a model lamb carcass, Journal of Food Engineering 61 (2004) 421-429.

[26] J. Willix, M.B. Harris, J.K. Carson, Local surface heat transfer coefficients on a model beef side, Journal of Food Engineering 74 (2006) 561-567.

[27] A. Kondjoyan, G. Alvarez, Etude bibliographique sur les coefficients de transferts de chaleur et de matière convectifs entre l'air et un ensemble de produits -1 Du cylindre ou de la sphère isolés à un ensemble de 2 à 4 de ces objets, Entropie 32 (195) (1996) 51-62.

[28] P. Verboven, A.K. Datta, N.T. Anh, N. Scheerlinck, B. Nicolai, Computation of airflow effects on heat and mass transfer in a microwave oven, Journal of Food Engineering 59 (2003) 181-190.

[29] A. Kondjoyan, H.-C. Boisson, Comparison of calculated and experimental heat transfer coefficients at the surface of circular cylinders placed in a turbulent cross-flow of air, Journal of Food Engineering 34 (2) (1997) 123-143.

[30] Z. Hu, D.-W. Sun, Predicting the local surface heat transfer coefficients by different turbulent $k-\varepsilon$ models to simulate heat and moisture transfer during air-blast chilling, International Journal of Refrigeration 24 (2001) 702-717.

[31] A. Kondjoyan, Relation aéraulique - thermique: convection et rayonnement - Résolution des équations et exemples pratiques, Industrie Alimentaires Et Agricoles Oct. (2001) $16-19$.

[32] F. Péneau, H.-C. Boisson, A. Kondjoyan, N. Djilali, Structure of a flat plate boundary layer subjected to free-stream turbulence, International Journal of Computational Fluid Dynamics 18 (2) (2004) 175-188.

[33] A. Kondjoyan, F. Péneau, H.-C. Boisson, Development of flat-plate thermal and velocity boundary layers under highly turbulent and instable air flows: Reynolds numbers ranging from 8400 to 127,000 , International Journal of Thermal Science 43 (2004) 1091-1100. 